Supplement of Hydrol. Earth Syst. Sci. Discuss., 12, 7179-7223, 2015

http://www.hydrol-earth-syst-sci-discuss.net/12/7179/2015/

doi:10.5194/hessd-12-7179-2015-supplement

(C) Author(s) 2015. CC Attribution 3.0 License.

(c) (1)

Supplement of

\title{
Accounting for three sources of uncertainty in ensemble hydrological forecasting
}

\section{A. Thiboult et al.}

Correspondence to: A. Thiboult (antoine.thiboult.1@ulaval.ca)

The copyright of individual parts of the supplement might differ from the CC-BY 3.0 licence. 
Day 1

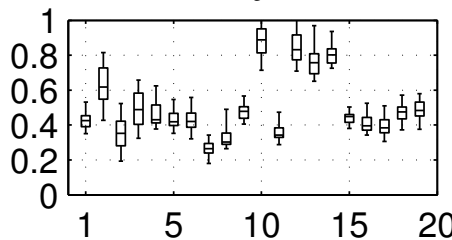
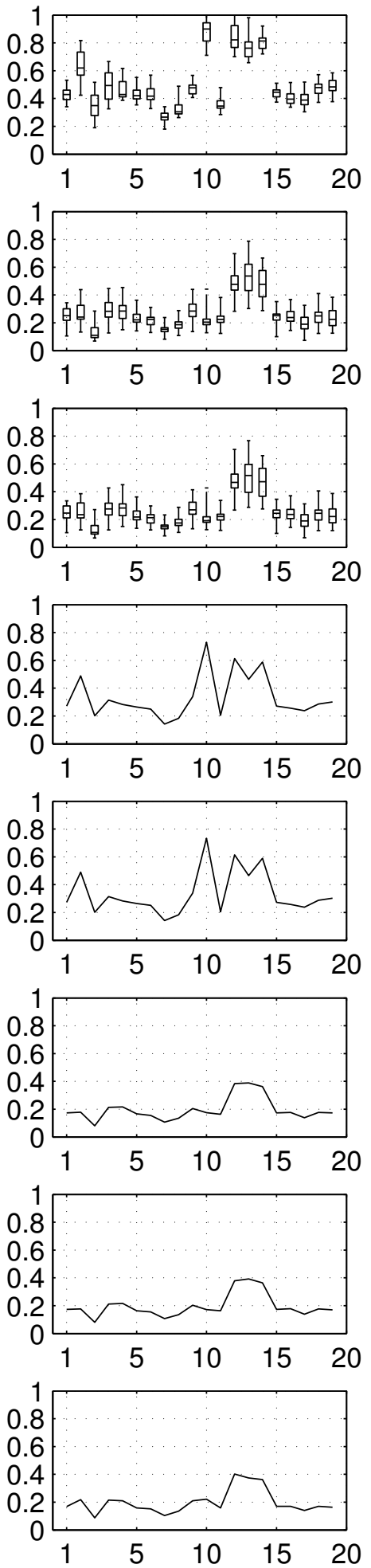

Catchments
Day 3

Day 6
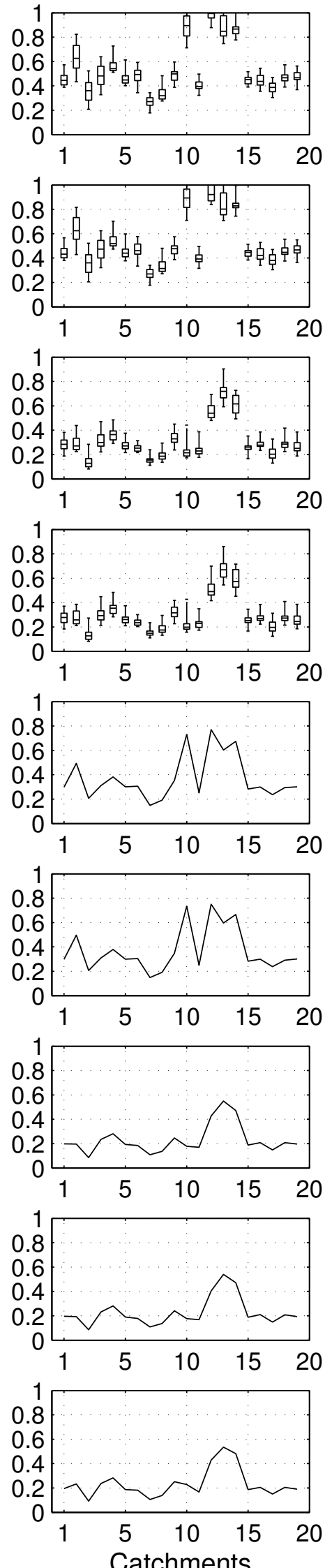

Day 9
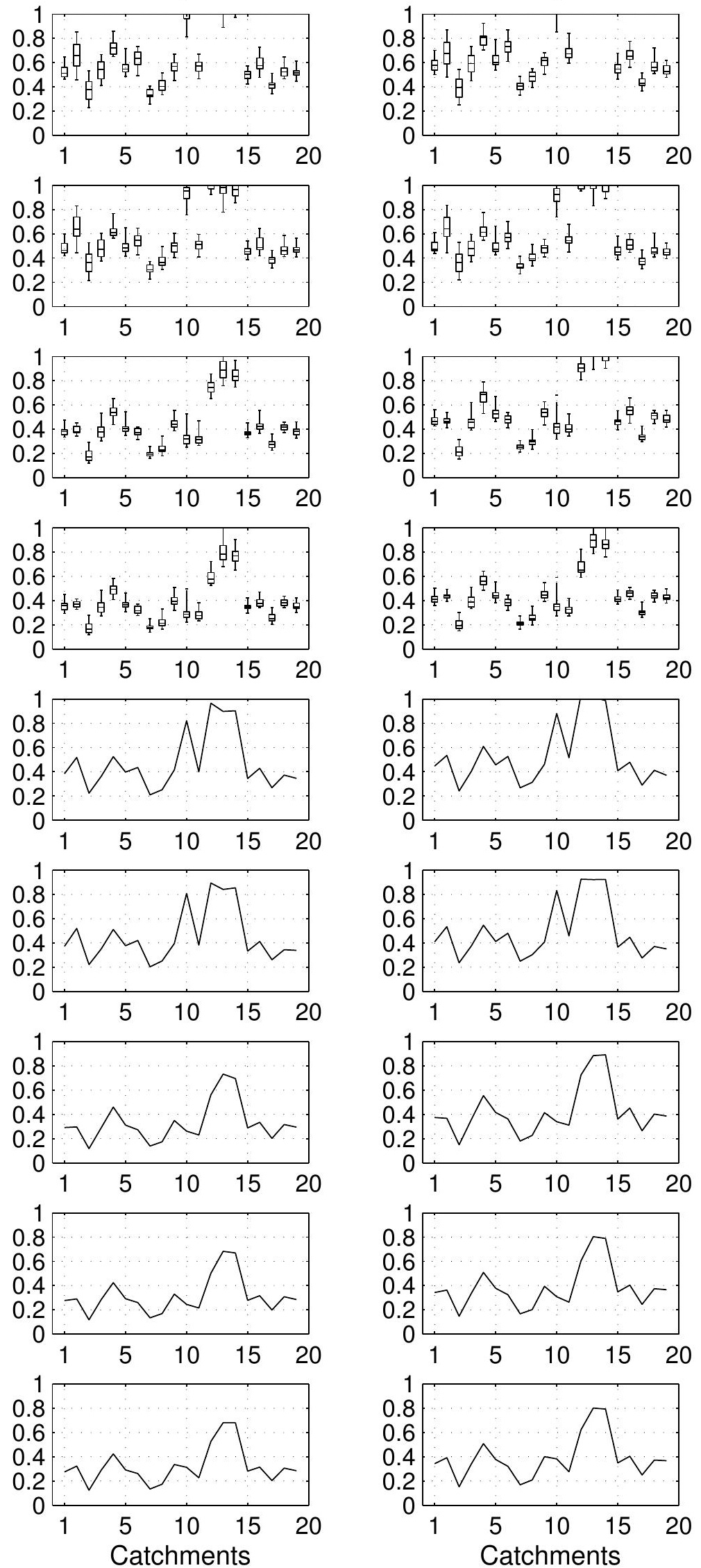
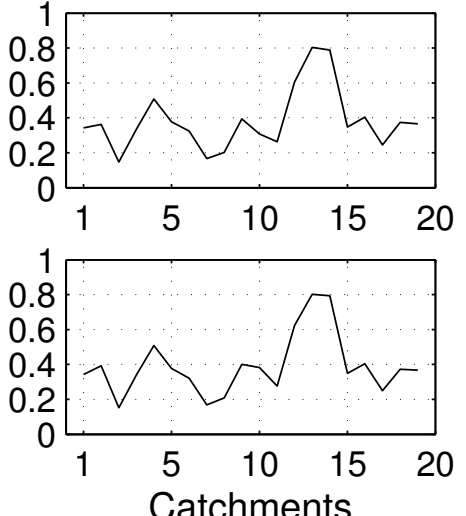
Day 1

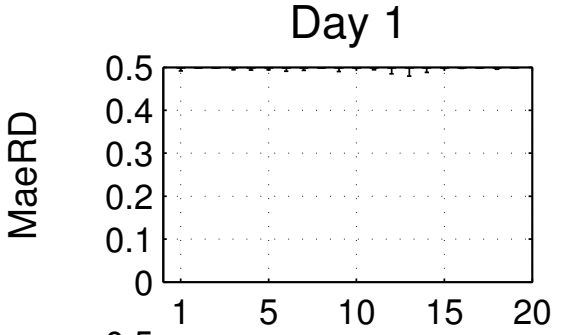

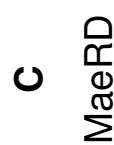

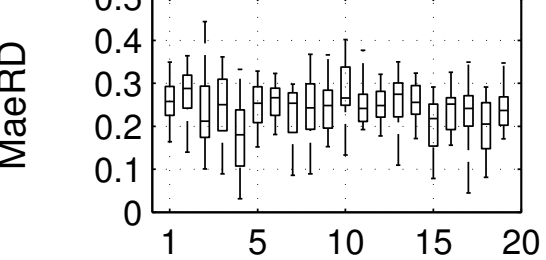

-
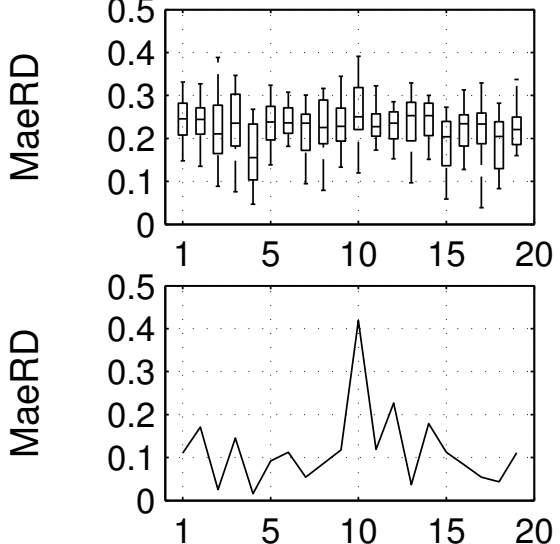

象

遭
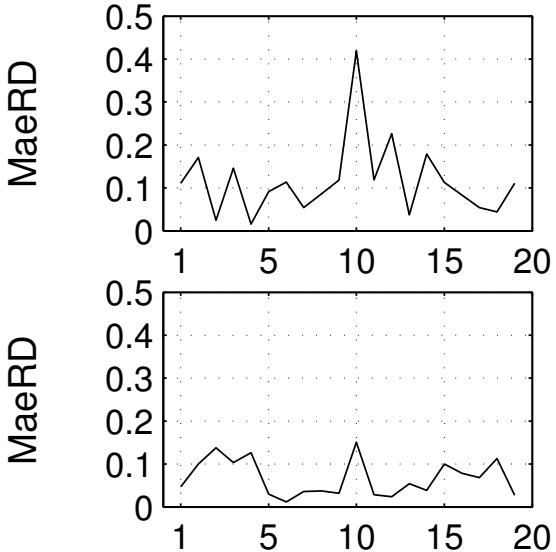

I
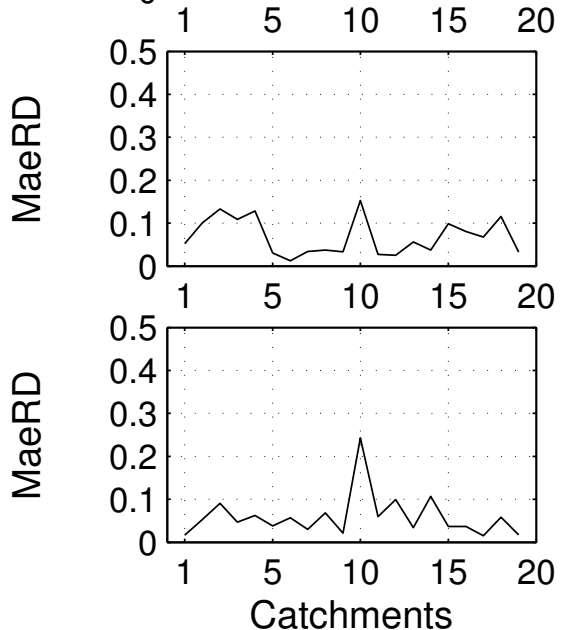

\section{Day 3}

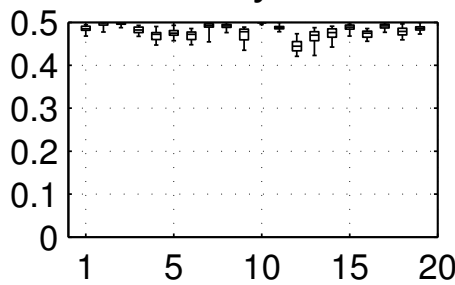

$\begin{array}{lllll}1 & 5 & 10 & 15 & 20\end{array}$

0.4 的绪的的白

0.2 l.

0.1
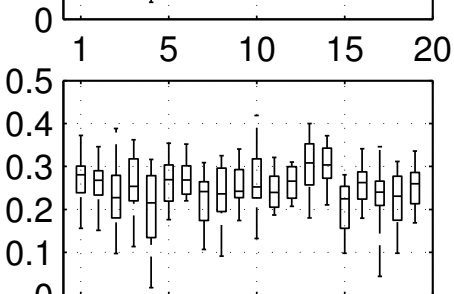

0.1
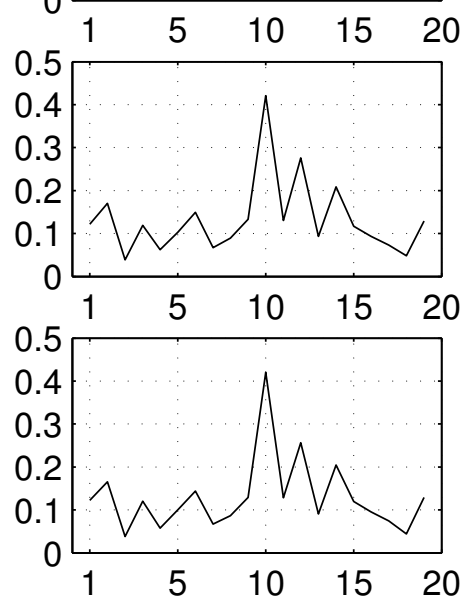

0.5

0.3

0.2
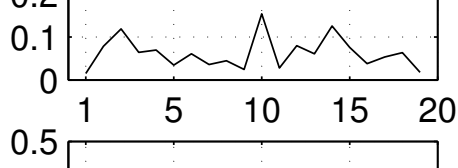

0.4

0.3

0.2 .
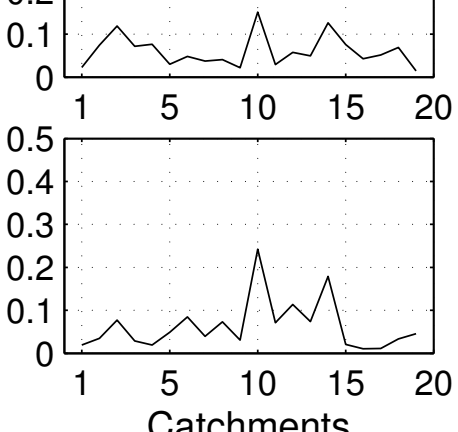

Day 6

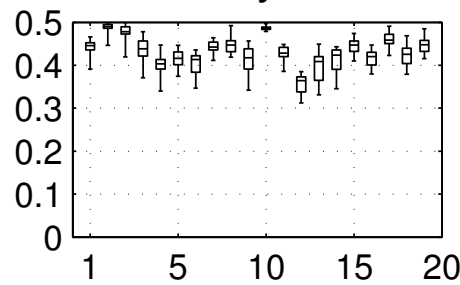

$0.5 \begin{array}{ccccc}1 & 5 & 10 & 15 & 20\end{array}$

0.4 的的的的的的的

0.2

0.1

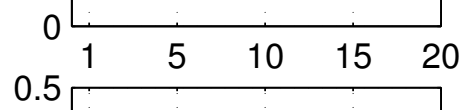

0.4 的的的的的的的

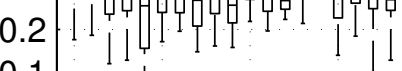

0.1

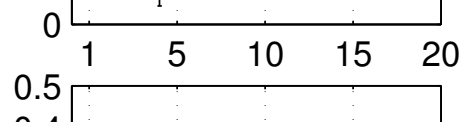

0.4

0.3

0.2

0.1

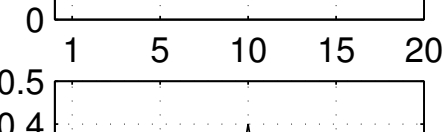

0.4

0.3

0.2

0.1

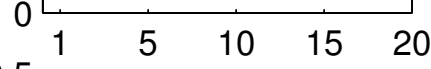

0.5

0.4

0.3

0.2
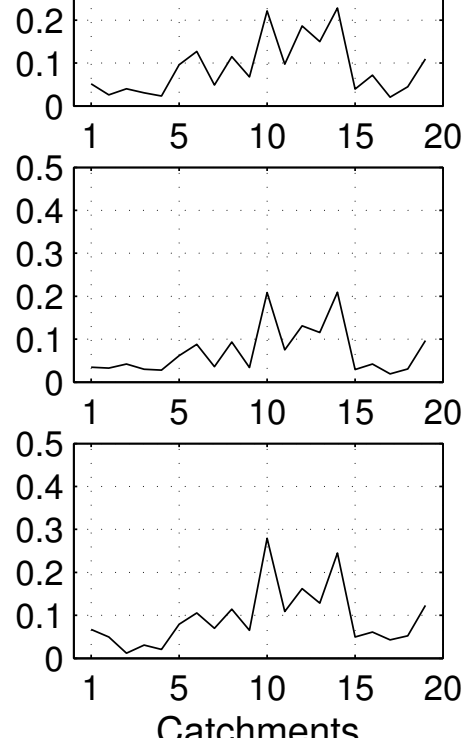

Day 9
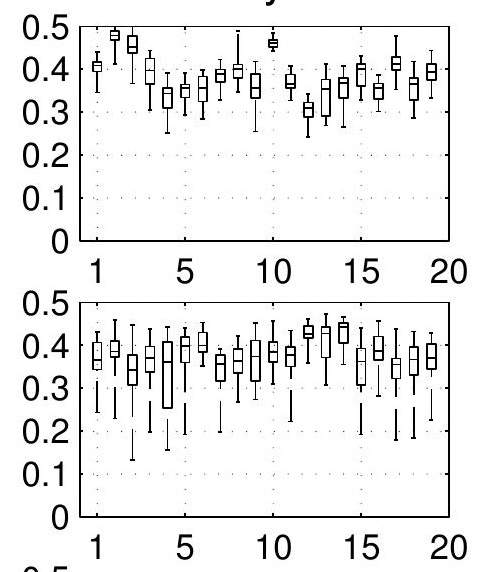

0.5
0.4
0.3
0.2
0.1

0.5
0.4
0.3
0.1

0.1
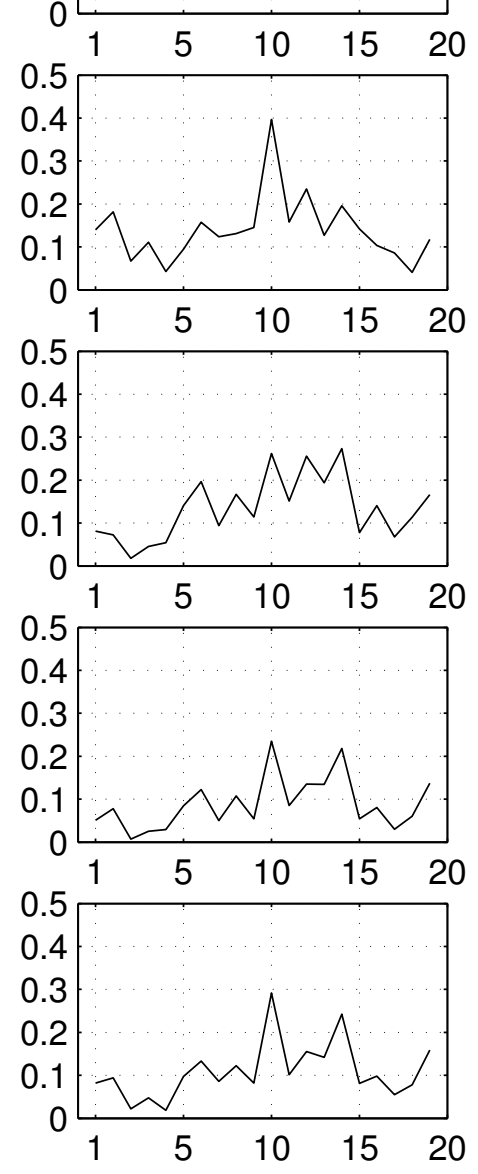

Catchments 
Day 1
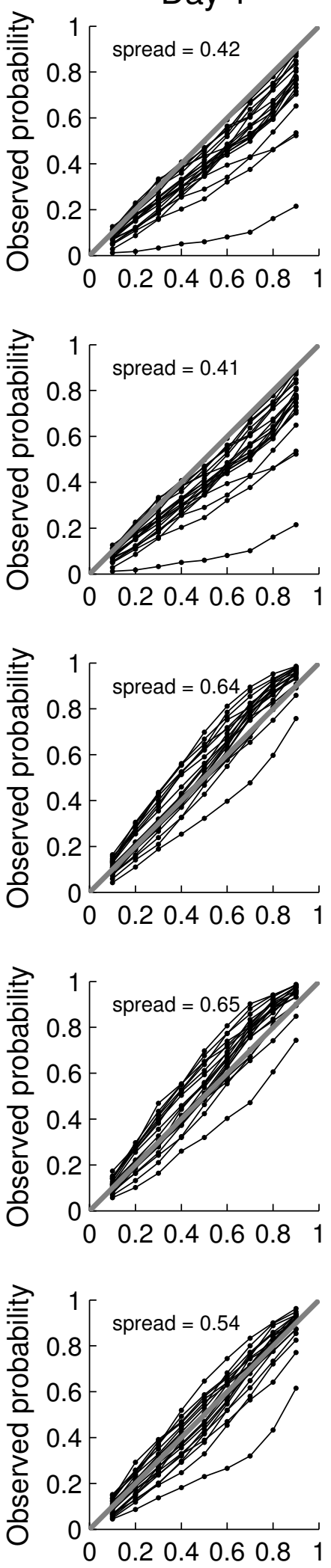

Forecast probability
Day 3
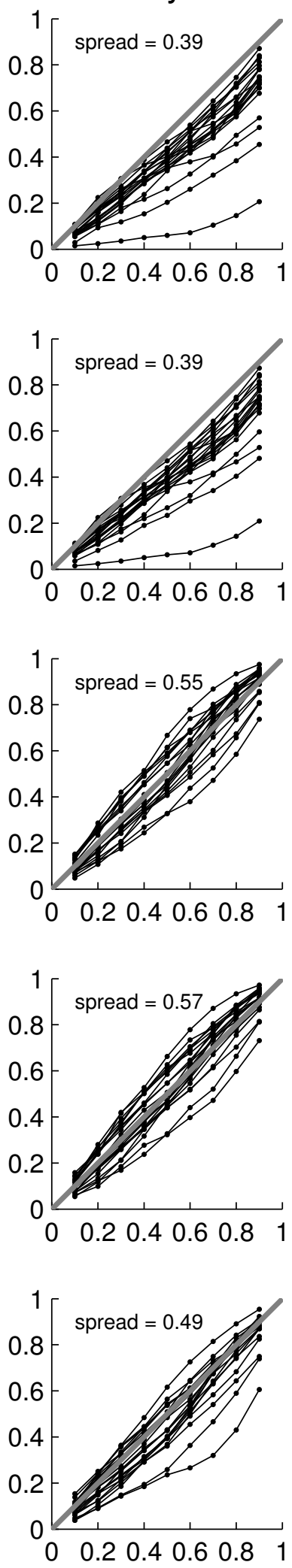

Forecast probability
Day 6
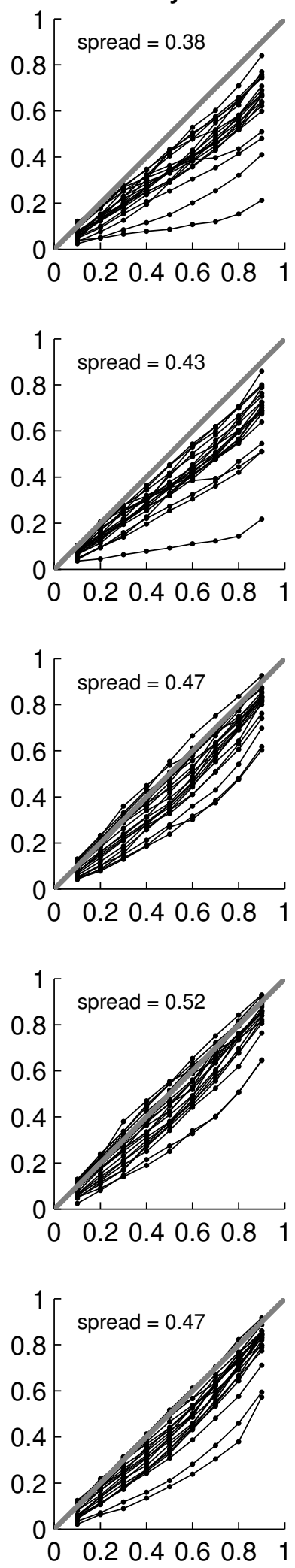

Forecast probability
Day 9
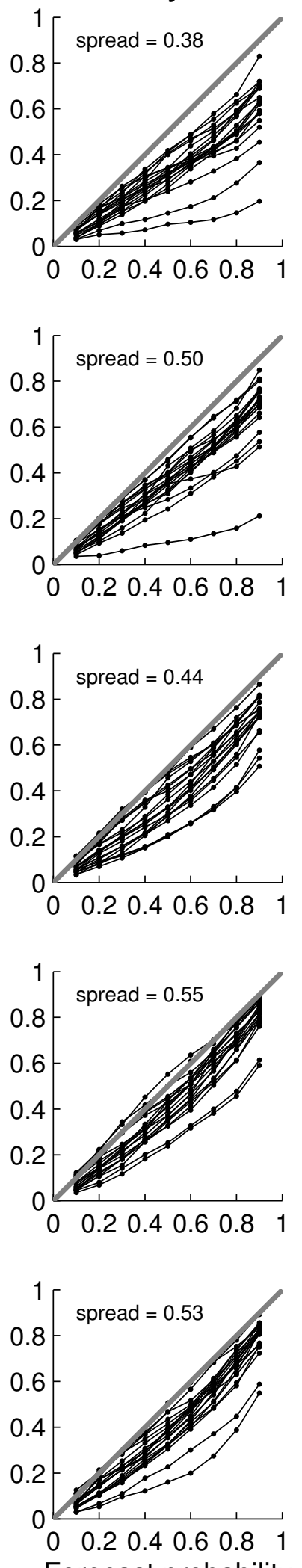

Forecast probability 